\title{
Occupational management in the workplace and impact on Workers' Compensation Board claims, duration, and cost: a prospective longitudinal cohort
}

This article was published in the following Dove Press journal:

Risk Management and Healthcare Policy

27 July 2016

Number of times this article has been viewed

\section{Mark E Lemstra \\ Alliance Health Medical Clinic, Moose Jaw, SK, Canada}

\begin{abstract}
Few workplaces have prospectively reviewed workplace and worker issues simultaneously and assessed their impact on Workers' Compensation Board (WCB) claims. In January of 2014, each worker in a large workplace in Saskatchewan, Canada, was prospectively followed for 1 year to determine factors that impact injury claim incidence, recovery, and costs. In total, 207 out of 245 workers agreed to complete the baseline survey (84.5\%). In 2014, 82.5\% of workers had self-reported pain, but only $35.5 \%$ submitted a WCB claim. Binary logistic regression was used to compare those with pain who did not submit a WCB injury claim to those with pain who did initiate a WCB claim. Independent risk factors associated with WCB claim incidence included depressed mood (odds ratio $[\mathrm{OR}]=2.75,95 \%$ confidence interval $[\mathrm{CI}] 1.44-9.78$ ) and lower job satisfaction $(\mathrm{OR}=1.70,95 \% \mathrm{CI} 1.08-10.68)$. Higher disability duration was independently associated with higher depressed $\operatorname{mood}(\mathrm{OR}=1.60,95 \% \mathrm{CI} 1.05-4.11)$ and poor recovery expectation ( $\mathrm{OR}=1.31,95 \% \mathrm{CI} 1.01-5.78)$. Higher cost disability claims were independently associated with higher depressed $\operatorname{mood}(\mathrm{OR}=1.51,95 \% \mathrm{CI} 1.07-6.87)$ and pain catastrophizing $(\mathrm{OR}=1.11,95 \% \mathrm{CI} 1.02-8.11)$. Self-reported pain, physically assessed injury severity, and measured ergonomic risk of workstation did not significantly predict injury claim incidence, duration, or costs. In January 2015, the workplace implemented a new occupational prevention and management program. The injury incidence rate ratio reduced by 58\% from 2014 to 2015 (IRR $=1.58,95 \% \mathrm{CI}=1.28-1.94)$. The ratio for disability duration reduced by $139 \%$ from 2014 to 2015 ( $R R=2.39,95 \% C I=2.16-2.63$ ). Costs reduced from $\$ 114,149.07$ to $\$ 56,528.14$ per year. In summary, WCB claims are complex. Recognizing that nonphysical factors, such as depressed mood, influence injury claim incidence, recovery, and costs, can be helpful to claims management. Keywords: workplace, Workers Compensation Board, injury claim, depressed mood, returnto-work program, job satisfaction
\end{abstract}

\section{Introduction}

Workers Compensation Board (WCB) injuries are complex. As such, treatment-focused programs in isolation have not reduced injury claim incidence, duration, or cost in the workplace. ${ }^{1-3}$

For example, the Institute for Work and Health (IWH) systematically reviewed injury prevention and loss control. The only intervention to demonstrate a strong level of evidence was proactive return-to-work programs, which included on-site education and offered return to work with modified duties. A moderate level of evidence was found for employee support and daily exercise. ${ }^{4}$

The IWH also performed a second systematic literature review on workplace returnto-work programs. No intervention had high levels of evidence for reducing claim
Correspondence: Mark E Lemstra Alliance Health Medical Clinic, $890 \mathrm{~A}$ Lillooet St W, Moose Jaw, SK S6H 8B4, Canada

Tel +l 30623039 II

Email marklemstra@shaw.ca 
incidence, duration, or costs. A moderate level of evidence was found for seven interventions, including 1) immediate contact with the worker and job accommodation; 2) independent ergonomic assessments with the goal of return-to-work coordination; 3) on-site education with supervisors and managers on how to facilitate early return to work; 4) active participation from workers in the return-to-work process; 5) creating conditions of goodwill; 6) avoiding miscommunication; and 7) allowing on-site, independent occupational health professionals to bridge communication between management, workers, and external health care practitioners. ${ }^{5}$

The IWH also performed a third systematic literature review on prognostic factors that negatively influence worker (not workplace) disability time. Strong evidence was found for five prognostic factors, including 1) worker's poor recovery expectations; 2) passive (not active) rehabilitation; 3) worker's self-report high pain intensity; 4) radiating pain; and 5) poor job satisfaction. ${ }^{6}$

Aside from IWH, four systematic literature reviews have also been conducted by the Cochrane Collaboration. One review found that exercise for the treatment of back pain reduces the number of recurrences of back pain. ${ }^{7}$ Similarly, a second review found that advice to stay active after a low back injury was more effective in pain relief and ability to perform work in comparison to bed rest. ${ }^{8} \mathrm{~A}$ third review found that back education in occupational settings reduced pain, increased function, and improved return-to-work status. ${ }^{9} \mathrm{~A}$ fourth review found that off-site work hardening programs had no effect on disability duration. ${ }^{10}$

There are five additional systematic literature reviews that were not published by either the IWH or Cochrane. One found evidence to support exercise in the prevention of occupational back pain. ${ }^{11}$ Similarly, another review concluded that there was strong evidence to support exercise for both treatment and prevention of back pain in the workplace. ${ }^{12} \mathrm{~A}$ third review found that advice to keep active was sufficient for acute work injuries, but specific exercises were required for subchronic and chronic occupational back injuries. ${ }^{13} \mathrm{~A}$ fourth review concluded that the best overall intervention to promote early return to work after an occupational injury was combining clinical interventions with occupational interventions, including modified work duties. ${ }^{14}$ Finally, the fifth review concluded that the most effective interventions at promoting return to-work were those that combined employers, employees, and health practitioners working together to implement work modifications. ${ }^{15}$

The first objective of the current study was to determine which factors prospectively determined WCB injury claim incidence, higher duration, and higher costs. The second objective was to determine if a new, comprehensive occupational program reduced injury claim incidence, duration of disability time, and costs. This program included on-site education, ergonomic evaluations, advice to stay active, immediate contact with workers, support from managers and union, enhanced communication, proactive offer of return to work with modified duties, and independent on-site physical and occupational therapists

\section{Methods}

In January of 2014, each worker at a large company (meat company with kill floor, processing area, and shipping) in Saskatchewan, Canada, was asked to complete a confidential survey that was voluntary. There was no inclusion or exclusion criteria. Because intervention was requested by both management and the union, the survey was voluntary, results were placed in a sealed envelope with confidentiality and privacy assured by the independent researchers, and the results were stored in the confidential file area of a medical clinic with experience in privacy and health information protection. Because the intervention was jointly requested by the union and its workers as part of a broad proactive health initiative, external ethics review was not required.

\section{Measurement}

Based on the literature review, the survey was designed to collect information on demographics, job satisfaction, selfreport health, depressed mood, general health status, and pain. Questions addressing drug use, alcohol use, and suicide ideation were prohibited by the union.

Questions on demographics, job satisfaction, and selfreport health came from the Canadian Community Health Survey conducted by Statistics Canada. ${ }^{16}$ The Beck Depression Inventory II (BDI-II) was used to measure depressed mood. ${ }^{17}$ This survey has good internal scale reliability for community-dwelling adults (Cronbach's $\alpha=0.86-0.92){ }^{18}$ Those who scored 11 or higher on the BDI-II were considered to have depressed mood. The Short Form-36 (SF-36) was used to measure general health status. ${ }^{19}$ The SF-36 is a commonly used instrument that measures eight dimensions of self-report health, quality of life, and function.

Participants also completed a pain scale and a visual analog scale measuring pain from 0 (no pain) to 10 (as bad as it can be) for 1) average pain and for 2) pain at its worst over the past week. ${ }^{20,21}$ Coping with pain and expectation of recovery was measured with the Pain Catastrophizing Scale. The Pain Catastrophizing Scale is well known, with 
established reliability $(r=0.75)$ and validity (scale explains $59 \%$ of variance in pain). ${ }^{22}$

Ergonomic risk of injury included direct measurement of each workstation by an occupational therapist. The occupational therapist used the WorkSmart Ergonomic Systems Specialist program to code all workstations into either low, medium, or high risk of injury. Low risk was defined as only one significant exposure to musculoskeletal injury, moderate risk was two significant exposures, and high risk was three or more significant exposures to musculoskeletal injury. ${ }^{23}$

\section{Intervention}

In 2014, each worker was asked to present to an on-site occupational therapist for musculoskeletal screening. If the worker had pain, the injury was coded as 1 (pain, stiffness, or tenderness without physical signs), 2 (pain and musculoskeletal signs), 3 (pain and neurological signs), or 4 (pain and fracture or dislocation). The classifications came from the Quebec Task Force for neck and back pain. ${ }^{24}$

Binary logistic regression was used to compare those with pain who did not submit a WCB injury claim to those with pain who did initiate a WCB claim in 2014. Regression was used to compare higher duration claims (top 50\%) to lower duration WCB injury claims (lower 50\%) and higher cost claims (top 50\%) to lower cost WCB injury claims (lower $50 \%$ ) in 2014. In total, 24 self-report survey variables, ergonomic workstation risk variables, and direct physical evaluation variables were included for analysis. The unadjusted effect of each covariate was determined and then entered one step at a time based on changes in the $-2 \log$ likelihood and the Wald test. The final results are presented as adjusted odds ratios (ORs) with $95 \%$ confidence intervals (CIs). ${ }^{25}$

The management (January 5, 2015) and the union (January 15,2015$)$ signed a contract for an on-site occupational management program. Any worker with pain or stiffness was encouraged to see the on-site independent occupational therapist or physical therapist for education (ie, stretches), advice to stay active, enhanced communication between the worker and supervisor, and proactive offer of return to work with modified duties. The program did not provide on-site treatment. If a worker had a serious injury, they were advised to go to their family physician. The occupational management intervention was 1 hour a day, 5 days a week, for 1 year. The program was based on an evidence-based review of the literature described previously. ${ }^{5-15}$

Ergonomic evaluations and recommendations on 77 workstations took 154 hours, whereas physical assessments of 207 workers took 69 hours. The WCB results were analyzed on February 3, 2016 to allow sufficient time for claims adjudication.

\section{Results}

In 2014 and 2015, the company had 245 full-time workers. For data collection in 2014, 207 out of 245 workers agreed to complete the questionnaire ( $84.5 \%$ response rate). Job satisfaction was low, with $73.2 \%$ not at all satisfied with work. The prevalence of depressed mood was high, with $33.8 \%$ reporting mild depressed mood and another $7.2 \%$ reporting moderate-to-severe depressed mood (41\% with depressed mood). In total, $82.5 \%$ of the workforce reported pain at least once per week. The complete results are listed in Table 1.

Ergonomic risk of injury included direct measurement of each of the 77 workstations by an occupational therapist. Low risk was detected at 22 workstations, moderate risk was detected at 46 workstations, and high risk was detected at 9 workstations. The results are listed in Table 2. Among those who completed the survey, the occupational therapist coded the injuries as Level 1 (93\% with pain or stiffness or tenderness but without any physical signs) or Level 2 (7\% with pain and musculoskeletal signs), with no Level 3 or Level 4 injuries found. Those with musculoskeletal signs were advised to consider seeing their family physician. Three workers with WCB claims refused to be physically assessed by the therapist. This was permitted due to the voluntary nature of the intervention.

For pain catastrophizing, the scores were relatively low, with means ranging from 0.46 to 1.21 out of a maximum score of 4 .

Binary logistic regression was used to compare those with pain who did not submit a WCB injury claim to those with pain who did initiate a WCB claim in 2014. Completing a WCB injury claim, in comparison to not initiating a WCB claim, was independently associated with higher depressed $\operatorname{mood}(\mathrm{OR}=2.75,95 \% \mathrm{CI} 1.44-9.78)$ and lower job satisfaction $(\mathrm{OR}=1.70,95 \%$ CI 1.08-10.68).

Regression was used to compare higher duration claims (top 50\%) to lower duration WCB injury claims (lower $50 \%$ ) in 2014. Higher disability duration was independently associated with higher depressed $\operatorname{mood}(\mathrm{OR}=1.60,95 \% \mathrm{CI}$ 1.05-4.11) and poor recovery expectation $(\mathrm{OR}=1.31,95 \%$ CI 1.01-5.78).

Regression analysis was also used to compare higher cost claims (top 50\%) to lower cost WCB injury claims (lower $50 \%$ of costs) in 2014. Higher cost disability claims were independently associated with higher depressed mood $(\mathrm{OR}=1.51,95 \% \mathrm{CI} 1.07-6.87)$ and pain catastrophizing (OR $=1.11,95 \%$ CI 1.02-8.11). 
Table I Survey of workers

\begin{tabular}{ll}
\hline Variable & Percent \\
\hline Sex & \\
$\quad$ Male & $69.2 \%$ \\
$\quad$ Female & $30.8 \%$ \\
Marital status & \\
$\quad$ Married or common law & $56.1 \%$ \\
Single & $43.9 \%$ \\
Education & \\
$\quad$ University degree or college diploma & $7.7 \%$ \\
$\quad$ High school diploma & $52.7 \%$ \\
$\quad$ Less than high school diploma & $39.6 \%$ \\
Age (years) & \\
Mean (min, max) & $34.7(18,64)$
\end{tabular}

Overall, how satisfied are you with your job

Very satisfied

Satisfied

$19.3 \%$

$7.5 \%$

Not at all satisfied

Overall, how satisfied are you with your supervisors

Very satisfied

Satisfied

Not at all satisfied

Overall, how satisfied are you with your coworkers

Very satisfied

Satisfied

Not at all satisfied

Overall, how satisfied are you with levels of communication

Very satisfied

Satisfied

Not at all satisfied

$73.2 \%$

$37.6 \%$

$57.9 \%$

$4.5 \%$

$24.7 \%$

$70.8 \%$

$4.5 \%$

$21.0 \%$

$73.7 \%$

$5.3 \%$

What are your opportunities for promotion

Very good

$23.4 \%$

Good

Not good

$56.7 \%$

$19.9 \%$

How likely is it you will leave company in next 12 months Very likely

Likely

Not likely

How well did you perform your work duties last year Extremely well

$68.2 \%$

$40.1 \%$

Well

$57.9 \%$

Not at all well

$1.9 \%$

Do you do shift work

Yes

$28.9 \%$

No

$71.1 \%$

Length of employment at company (months)

Mean (min, max)

In general, would you say your health is ${ }^{16}$

Excellent

Very good

Good

Fair

Poor

In general, would you say your mental health is ${ }^{16}$

Excellent

Very good

Good

Fair

Poor

Depressed mood score (BDI-II) ${ }^{17,18}$

$4.8 \%$

$24.5 \%$

$53.1 \%$

$16.8 \%$

$0.8 \%$

$4.8 \%$

$12.1 \%$

$43.5 \%$

$29.0 \%$

$10.6 \%$
Table I (Continued)

\begin{tabular}{ll}
\hline Variable & Percent \\
\hline No depressed mood & $59.0 \%$ \\
Mild/borderline & $33.8 \%$ \\
Moderate/severe & $7.2 \%$ \\
During past week, how often have you had physical & \\
discomfort or pain & \\
Never & $17.5 \%$ \\
Once or twice & $45.3 \%$ \\
Fairly often & $29.0 \%$ \\
Very often & $7.2 \%$ \\
Every day or almost & $3.0 \%$
\end{tabular}

Circle the number that best describes your pain on average over the past week $(0-10)^{20,21}$

Average pain score (mean)

$1.79 / 10$

Circle the number that best describes your pain at its worst over the past week $(0-10)^{20,21}$

Worst pain score (mean)

$4.59 / 10$

Do you think your injury (if injured) will

Get better soon

$72.5 \%$

Get better slowly

$9.7 \%$

Never get better

$11.6 \%$

Do not know

$6.2 \%$

Pain catastrophizing and expectation of recovery (PCS survey $)^{22}$

Worry all the time about whether pain will end $\quad 0.49 / 4$

I feel I can't go on $\quad 0.46 / 4$

It's terrible and I think it's never going to get better $\quad 0.59 / 4$

I feel like I can't stand it anymore $\quad 0.52 / 4$

I become afraid that the pain will get worse $\quad 0.95 / 4$

I keep thinking of other painful events $\quad 0.56 / 4$

I can't seem to get it out of my mind $\quad 0.75 / 4$

I keep thinking about how much it hurts $\quad 0.7 \mathrm{I} / 4$

I keep thinking how badly I want the pain to stop $\quad 0.59 / 4$

There's nothing I can do to reduce the intensity of the pain $\quad 0.3 \mathrm{I} / 4$

$\begin{array}{ll}\text { I wonder whether something serious will happen } & \text { I.2I/4 }\end{array}$

General health, quality of life, and function (SF-36 survey -

mean scores) ${ }^{19}$

Physical functioning 61.9

Role limitations due to physical health 58.1

Pain $\quad 63.8$

General health $\quad 50.3$

Vitality 4I.I

Social functioning $\quad 68.8$

Role limitation due to emotional health 48.1

Emotional well-being 51.1

I4.4 (I, 240) Times visited family physician last month (mean) 0.92

Times visited hospital last 3 months (mean) 0.39

(Continued)
Notes: $\mathrm{n}=207 / 245$ or $84.5 \%$ response rate; ${ }^{\mathrm{a}}$ Answers: 0 - not at all; I - to a slight degree; 2 - to a moderate degree; 3 - to a great degree; 4 - all the time; Mean (average) from 0 to 4 reported in table.

Abbreviations: BDI-II, Beck Depression Inventory II; PCS, Pain Catastrophizing Scale; SF-36, Short Form-36, min, minimum; max, maximum.

Through regression analysis, it was found that self-report pain, physically assessed injury severity, and measured ergonomic risk of workstation with an occupational therapist did not significantly predict injury claim incidence, duration, or costs.

The results for all three regression analyses can be found in Table 3. In 2014, there were 87 WCB injuries (28 time loss 
Table 2 Ergonomic risk of workstations measured by occupational therapist

A. Low risk - Only one significant exposure to musculoskeletal injury (22 workstations)

Cryovac area - None; Cut floor - Sort I, Sort 2, Skins; Shipping and Receiving - Fork lift, Inventory, Loin puller; Cut floor break line - Loin puller; Box room - Box chute; Kill line - Herd chute, stunner; Miscellaneous - Knife room; Red offal room - None; Laperminentierre room - Bander, Bone sorter, Pack off; Cut floor (leg belly line) - None; Cut floor (shoulder line) - None; Kill floor - Bottom shave, Bottom trim, Ear, Jowl, Probe, Tongue, Top shave, Verification, Top trim.

\section{B. Medium risk - Two significant exposures to musculoskeletal injury (46 workstations)}

Cryovac area - Box chute, Detection, Labeling, Packaging, Press; Cut floor - Clean up, Carrier, Back fat; Shipping and Receiving - Scale, Palletizing prep, Tenderloin; Cut floor break line - Tenderloin; Box room - Box builder, Box taping; Kill line - Barn, Sticker; Miscellaneous - Roller game room; Red offal room - Upper sort, Lower sort, Conveyor, Box builder; Laperminentierre room - Scale; Cut floor (leg belly line) - Band saw, Belly marker, Belly trimmer, Jowls, Sirloin, Skinner, Tails; Cut floor (shoulder line) - Band saw, Blade bone remover, Neck boner, Picnic boner, Skinner, Shoulder cap wizard, Specialty katurosa, Splitting shoulders, Tenderloin; Kill floor - Brisket saw, Bung, Gutting, Oscillating saw, Pre gut, Red offal harvest, White offal harvest, Clean up.

\section{High risk - Three or more significant exposures to musculoskeletal injury ( 9 workstations)}

Cryovac area - Palletizing; Cut floor - None; Shipping and Receiving - Manual loading truck, Palletizing swamper; Cut floor break line - Belly loin breaker, Leg break saw; Box room - None; Kill line - None; Miscellaneous - Gamming, Hog pushing; Red offal room - Packager; Laperminentierre room - Palletizing; Cut floor (leg belly line) - None; Cut floor (shoulder line) - None; Kill floor - None.

Note: Data from Worksmart Ergonomics Ltd. ${ }^{23}$

Table 3 Independent risk factors for initiating WCB injury claim, higher injury duration, and higher injury cost

\begin{tabular}{|c|c|c|c|}
\hline & Odds ratio & $95 \% \mathrm{Cl}$ & $P$-value \\
\hline \multicolumn{4}{|l|}{ Model I } \\
\hline \multicolumn{4}{|c|}{ Comparing workers with pain and WCB claim to those with pain and no } \\
\hline \multicolumn{4}{|l|}{ WCB claim } \\
\hline \multicolumn{4}{|l|}{ Depressed mood } \\
\hline Depressed & 2.75 & I.44-9.78 & 0.005 \\
\hline \multicolumn{4}{|l|}{ Job satisfaction } \\
\hline Not at all satisfied with job & 1.70 & $1.08-10.68$ & 0.045 \\
\hline \multicolumn{4}{|l|}{ Model 2} \\
\hline \multirow{2}{*}{\multicolumn{4}{|c|}{$\begin{array}{l}\text { Comparing higher duration claims (top } 50 \% \text { ) to lower duration WCB } \\
\text { injury claims (lower } 50 \% \text { of duration) }\end{array}$}} \\
\hline & & & \\
\hline \multicolumn{4}{|c|}{ Depressed mood } \\
\hline Depressed & 1.60 & $1.05-4.11$ & 0.010 \\
\hline \multicolumn{4}{|l|}{ Recovery expectation } \\
\hline Injury will never get better & 1.31 & $\mathrm{I} .0 \mathrm{I}-5.78$ & 0.037 \\
\hline \multicolumn{4}{|l|}{ Model 3} \\
\hline \multicolumn{4}{|c|}{$\begin{array}{l}\text { Comparing higher cost claims (top 50\%) to lower cost WCB injury } \\
\text { claims (lower } 50 \% \text { of costs) }\end{array}$} \\
\hline \multicolumn{4}{|c|}{ Depressed mood } \\
\hline Depressed & 1.51 & $1.07-6.87$ & 0.041 \\
\hline \multicolumn{4}{|l|}{ Pain catastrophizing } \\
\hline $\begin{array}{l}\text { I feel I can't go on to a great } \\
\text { degree or all the time }\end{array}$ & I.II & $1.02-8.11$ & 0.047 \\
\hline
\end{tabular}

Notes: Reference categories: Model I - no depressed mood, satisfied, or very satisfied with job; Model 2 - no depressed mood, injury will get better soon, or injury will get better slowly; Model 3 - no depressed mood, I feel I can't go on - not at all, to a slight degree, to a moderate degree.

Abbreviations: WCB, Workers' Compensation Board; Cl, confidence interval.

and 59 no time loss), a combined disability duration time of 403 days and a total cost of $\$ 114,149.07$. In January 2015 , the workplace implemented a new occupational program. In response, in 2015, there were 55 WCB injuries (15 time loss and 40 no time loss), a combined disability duration time of 169 days and a total cost of $\$ 56,528.14$. Computing an injury incidence rate ratio from 2014 to 2015 resulted in a ratio of 1.58 (95\% CI 1.28-1.94). Computing a ratio for disability duration from 2014 to 2015 resulted in a ratio of 2.39 (95\% CI 2.16-2.63).

\section{Discussion}

Work-related injuries and subsequent WCB claims are complex. For that reason, treatment-focused programs working in isolation have not reduced injury claim incidence, duration, or cost in the workplace. ${ }^{1-3}$

The current study found that depressed mood was associated with injury claim incidence, longer disability duration, and higher costs. In a systematic literature review of predictors of failure to return to work, the authors concluded that recovery expectation and fear avoidance are predictive of outcome, but that depression, job satisfaction, and psychological strain are not. ${ }^{26}$ The first two conclusions are consistent with our study, whereas the others are inconsistent. A possible explanation could be that this systematic literature review included only nonchronic cases (less than 3 months), nonspecific back pain, and complete failure to return to work in its inclusion criteria. ${ }^{26}$ In comparison, our study included acute and chronic cases, specific and nonspecific back pain, as well as all other musculoskeletal injuries. We also included those who returned to work and those who did not.

The finding that job satisfaction impacts recovery has been found in other systematic literature reviews. ${ }^{6}$ In that review, poor job satisfaction was found to delay recovery by $35 \% .{ }^{6}$ The impact of recovery expectation is also not new. In a prospective study of 1,566 injured workers looking specifically at the impact of recovery expectations, the authors found that this one variable explained one-sixth of the variation in duration of disability benefits received. ${ }^{27}$ This finding is consistent with a systematic literature review. ${ }^{6}$ 
The impact of depressed mood or depression has received less attention. As mentioned previously, one systematic literature review did not find that depression impacted return to work in those with very specific inclusion criteria: nonchronic cases, with nonspecific back pain who never returned to work. ${ }^{26}$ With more general inclusion criteria, the result may be different. For example, in a large study of 367,900 injured and noninjured workers, injured workers were much more likely (45\%) to be suffering from depression than noninjured workers. ${ }^{27}$

In our study, $84.5 \%$ of the workplace had self-report pain, but only $35.5 \%$ submitted a WCB claim. In another study of 1,598 injured employees, only $25 \%$ of workers with a musculoskeletal injury filed a WCB claim. Factors that impacted the decision to file WCB claims, in comparison to not filing claims, despite the presence of an injury, included shorter employment duration with company, dissatisfaction with coworkers, and lower income. ${ }^{28}$

Consistent with the evidence, our study found that having an on-site, independent occupational therapist or physical therapist to provide education and advice to stay active, as well as offering return to work with modified duties resulted in a significant reduction in injury claim incidence, duration, and costs..$^{5-15}$

A limitation to our study is that it only included information until February 3, 2016. Given WCB claims adjudication, it is possible that claims that were originally accepted or rejected could be reversed upon appeal in the following year. Second, although injury severity did not influence outcomes, it is possible that musculoskeletal screening had an influence on outcome through a Hawthorne effect (behavior changes as a result of observation). Third, although this was a prospective study, some information was collected at the same time. For example, we could not determine if job dissatisfaction led to depressed mood or if depressed mood led to job dissatisfaction and so on. Fourth, our study did not include a control group. Finally, only $84.5 \%$ of workers completed the voluntary survey.

\section{Conclusion}

Independent risk factors associated with WCB claim incidence included depressed $\operatorname{mood}(\mathrm{OR}=2.75,95 \% \mathrm{CI} 1.44-9.78)$ and lower job satisfaction (OR $=1.70,95 \%$ CI $1.08-10.68$ ). Higher disability duration was independently associated with higher depressed mood (OR $=1.60,95 \% \mathrm{CI} 1.05-4.11)$ and poor recovery expectation ( $\mathrm{OR}=1.31,95 \%$ CI 1.01-5.78). Higher cost disability claims were independently associated with higher depressed mood (OR $=1.51,95 \%$ CI 1.07-6.87) and pain catastrophizing ( $\mathrm{OR}=1.11,95 \% \mathrm{CI} 1.02-8.11$ ).

In January of 2015, the workplace implemented a new occupational prevention and management program. The injury incidence rate ratio reduced by $58 \%$ from 2014 to 2015 (IRR $=1.58,95 \% \mathrm{CI}=1.28-1.94$ ). The ratio for disability duration reduced by 139\% from 2014 to 2015 (RR $=2.39,95 \% \mathrm{CI}=2.16-2.63$ ).

In summary, WCB claims are complex. However, it appears that recognizing that nonphysical factors (ie, depressed mood, low job satisfaction, recovery expectations) influence injury claim incidence, recovery, and cost can be helpful to claims management. For example, one systematic literature review suggests that asking a worker about job satisfaction at the start of a WCB injury claim can help identify those at higher risk of delayed recovery and in need of extra attention. ${ }^{6}$ By accepting this finding, evidence-based occupational programming can have a positive impact on the workplace and its workers.

\section{Disclosure}

The author reports no conflicts of interest in this work.

\section{References}

1. Lemstra M, Olszynski WP. The effectiveness of standard care, early intervention and occupational management in Workers' Compensation claims: Part 2. Spine (Phila Pa 1976). 2004;29:1573-1579.

2. Lemstra M, Olszysnki WP. The effectiveness of standard care, early intervention and occupational management in workers' compensation claims. Spine (Phila Pa 1976). 2003;28:299-304.

3. Frank JW, Brooker AS, DeMaio SE, et al. Disability resulting from occupational low back pain part 2: what do we know about secondary prevention? A review of the scientific evidence on prevention after disability begins. Spine (Phila Pa 1976). 1996;21:2918-2929.

4. Brewer S, King E, Amick BC, et al. A Systematic Review of Injury/ Illness Prevention and Loss Control Programs (IPC). Toronto, ON: Institute for Work and Health; 2008.

5. Franche RL, Cullen K, Clarke J, et al. Workplace-Based Return to Work Interventions: A Systematic Review of the Quantitative and Qualitative Literature. Toronto, ON: Institute for Work and Health; 2004.

6. Steenstra I, Irvin E, Heymans M, Mahood Q, Hogg-Johnson S. Systematic Review of Prognostic Factors for Worker's Time Away from Work Due to Acute Low Back Pain. Toronto, ON: Institute for Work and Health; 2011.

7. Choi BK, Verbeek JH, Tam WW, Jiang JY. Exercises for the prevention of recurrences of episodes of low back pain. Cochrane Database Syst Rev. 2011;(1):CD006555.

8. Dahm KT, Bruberg KG, Jamtvedt G, Hagen KB. Advice to rest in bed versus advice to stay active for acute low back pain and sciatica. Cochrane Database Syst Rev. 2010;(6):CD007612.

9. Heymans MW, van tulder MW, Easmail R, Bombardier C, Koes BW. Back schools for non-specific low back pain. Cochrane Database Syst Rev. 2004;(4):CD000261.

10. Schaafsma FG, Whelan $K$, van der Beek AJ, van der Es-Lambeek LC, Ojajarvi A, Verbeek JH. Physical conditioning as part of a return to work strategy to reduce sickness absence for workers with back pain. Cochrane Database Syst Rev. 2013;(8):CD001822.

11. van Poppel MN, Koes B, Smid T, Bouter LM. A systematic review of controlled clinic trials on the prevention of back pain in industry. Occup Environ Med. 1997;549(12):841-847.

12. Bell JA, Burnett A. Exercise for the primary, secondary and tertiary prevention of low back pain in the workplace: a systematic review. JOccup Rehabil. 2009;19(1):8-24.

13. Liddle SD, Gracey JH, Baxter GD. Advice for the management of low back pain: a systematic review of the randomized trials. Man Ther. 2007: 12(4);310-327. 
14. Williams RM, Westmorland MG, Lin Ca, Schmuk G, Creen M. Effectiveness of workplace rehabilitation programs in the treatment of work-related back pain: a systematic review. Disabil Rehabil. 2007;29(8): 607-624.

15. Caroll C, Rick J, Pilgrim H, Cameron J, Hillage J. Workplace involvement improves return to work rates among employees with back pain on long term sick leave: a systematic review of the effectiveness and cost effectiveness of interventions. Disabil Rehabil. 2010;32(8):607-621.

16. BélandY. Canadian community health survey - methodological overview. Statistics Canada, Catalogue 82-003. Health Rep. 2002;13(3):9-14.

17. Beck AT, Steer RA, Brown GK. Manual for the Beck Depression Inventory-II. San Antonio, TX: Psychological Corporation; 1996.

18. Segal DL, Coolidge FL, Cahill BS, O'Riley AA. Psychometric properties of the Beck Depression Inventory-II (BDI-II) among communitydwelling older adults. Behav Modif. 2008;32(1):3-20.

19. Ware JE, Kosinski M, Keller, SD. SF-36 Physical and Mental Health Summary Scales: A Users'Manual. Boston, MA: The Health Institute; 1994.

20. Jensen MP, Karoly P, Braver S. The measurement of clinical pain intensity: a comparison of six methods. Pain. 1986;27:117-126.
21. Margolis RB, Tait RC, Krause SJ. A rating system for use with patient pain drawings. Pain. 1986;24:57-65.

22. Sullivan MJL, Bishop SR, Pivik J. The Pain Catastrophizing Scale: development and validation. Psychol Assess. 1995;7(4):524-532.

23. Worksmart Ergonomics Ltd. Ergonomics Systems Specialist Certification USA. 2015. Available from: www.worksmart.ca

24. Spitzer WO, Skovron ML, Salmi LR, et al. Scientific monograph of the Quebec Task Force on Whiplash-Associated Disorders: redefining "whiplash" and its management. Spine. 1995;20(8S):1-73.

25. Rothman KJ, Greenland S. Modern Epidemiology. 2nd ed. Philadelphia PA: Lippincott Williams and Wilkins; 1998.

26. Iles RA, Davidson M, Taylor NF. Psychosocial predictors of failure to return to work in non-chronic non-specific low back pain: a systematic review. Occup Environ Med. 2008;65:507-517.

27. Cole DC, Mondloch MV, Hogg-Johnson S. Listening to injured workers: how recovery expectations predict outcomes - a prospective study. CMAJ. 2002;166(6):749-754.

28. Rosenman KD, Gardiner JC, Wang J, et al. Why most workers with occupational repetitive trauma do not file for Workers' Compensation. J Occup Environ Med. 2000;42:25.
Risk Management and Healthcare Policy

\section{Publish your work in this journal}

Risk Management and Healthcare Policy is an international, peer-reviewed open access journal focusing on all aspects of public health, policy, and preventative measures to promote good health and improve morbidity and mortality in the population. The journal welcomes submitted papers covering original research, basic science, clinical and epidemiological

\section{Dovepress}

studies, reviews and evaluations, guidelines, expert opinion and commentary, case reports and extended reports. The manuscript management system is completely online and includes a very quick and fair peerreview system, which is all easy to use. Visit http://www.dovepress.com/ testimonials.php to read real quotes from published authors.

Submit your manuscript here: https://www.dovepress.com/risk-management-and-healthcare-policy-journal 